\title{
Acute myelogenous leukaemia presenting with mid-foot pain after an inversion injury
}

\author{
C Dewar, H Morriss
}

\begin{abstract}
The case is presented of a 5 year old boy who attended after an inversion injury. He had persistent pain despite treatment and was subsequently diagnosed with acute myelogenous leukaemia. It is well recognised that acute leukaemia commonly presents as non-traumatic limb pain. This case highlights the need to consider acute leukaemia in the differential diagnosis of any persisting bone or joint pain, even in the context of recent injury.

(Emerg Med f 2001;18:143-144)
\end{abstract}

Keywords: leukaemia; inversion injury

Case report

A 5 year old boy presented after an inversion injury to his left ankle and foot two weeks previously. $\mathrm{He}$ complained of intermittent pain affecting his left foot since the time of the original injury. On examination he was found to be partial weight bearing, with associated swelling and tenderness on the lateral border of the mid-foot. The patient was treated as for a soft tissue injury and discharged.

$\mathrm{He}$ attended the following day with increasing pain over the mid-foot. At this time it was noted that he was non-weight bearing and there was evidence of increased warmth and erythema over the lateral border of the mid-foot. A diagnosis of cellulitis was made and oral cefaclor started.

$\mathrm{He}$ was subsequently seen one week later, at which time the erythema was resolving and he was fully weight bearing. In view of the lack of an obvious portal of entry for infection and persistent tenderness a radiograph was ordered, which was entirely normal. Two weeks later he re-attended with a further episode of mid-foot pain, at this time his parents also noted some weight loss. General examination revealed pallor but no evidence of lymphadenopathy or organomegaly. A full blood count taken at the time revealed a pancytopaenia (haemoglobin 8.1, white cell count 1.25, neutrophils 0.34 , lympocytes 0.88 , platelets 116) with no evidence of blasts in the blood film. A subsequent bone marrow aspirate confirmed acute myeloid leukaemia.

Accident and

Emergency

Department, Selly Oak

Hospital, Raddlebarn

Road, Birmingham

B29 6JD, UK

Correspondence to: Dr Dewar

(colin@dewar43.Fsnet.co.uk)

Accepted for publication 26 April 2000 tions of leukaemia is typically described as sharp, localised, severe and of sudden onset, it can also be intermittent in nature. ${ }^{8}$

Patients can present with overt "arthritis" with associated joint swelling. This "arthritis" is generally believed to be secondary to bone, periosteal, or capsular lesions rather than to direct synovial involvement. ${ }^{9}$ However, leukaemic infiltration of the synovium has been demonstrated in some patients, ${ }^{10}$ in others hyperuricaemia seems to play a part. ${ }^{11}$ Circulating immune complexes have been demonstrated in patients with various malignancies. ${ }^{12}$ Acute leukaemia may mimic a number of childhood rheumatic diseases, this can cause delay in diagnosis, a factor compounded by positive antinuclear antibody test results, which have been described in some patients. ${ }^{13}{ }^{14}$ Joints typically involved are the knees, hips, ankles and shoulders. Occasionally multiple joints may be involved. ${ }^{6}{ }^{13}$ Only one case involved the foot in a series of 10 reported cases by Schaller, this was a two year old girl who also showed involvement of the knees, ankle and elbow. ${ }^{6}$ Another series of six cases initially referred as childhood rheumatic diseases showed no cases with involvement of the foot. ${ }^{13}$ In both series the final diagnosis in all 16 cases was acute lymphoblastic leukaemia.

Heinrich et al, found $57 \%$ of children with acute lymphoblastic leukaemia had radiographic skeletal abnormalities at diagnosis. ${ }^{8}$ There are no pathognomic skeletal radiographic changes of acute leukaemia, it can however be associated with diffuse osteopenia, metaphyseal bands, periosteal new bone formation, geographical lytic lesions, sclerosis, mixed lysis/sclerosis, and permeative destruction.

Jonsson et al, in a review of 52 children with bone pain as the initial presentation of acute leukaemia found most had "nearly normal" haemoglobin levels and platelet counts on presentation. Only $6 \%$ had completely normal blood counts with no blasts on the film. Fifty per cent had no evidence of anaemia. Low leucocyte count was common on presentation $(37 \%)$, while a further $17 \%$ had a leucocyte count greater than 20 . In general the abnormalities on the blood count were mild. ${ }^{15}$ An increased lactate dehydrogenose concentration is recognised as being a useful marker of high cell turnover and has been found to have some discriminating value in patients with malignant neoplasms presenting with joint pains. $^{16}$

Acute leukaemia should be considered in the differential diagnosis of any non-traumatic limb pain in a child. This case illustrates the 
need to consider acute leukaemia in any persistent bone or joint pain, even if there is a history of recent injury. This case further emphasises that as in children with irritable hip a history of relatively minor injury can often deflect attention away from a more serious underlying cause for bone or joint pain. Radiographic changes may raise the suspicion of acute leukaemia but are not pathognomic and in $43 \%$ of children who present with bone pain and leukaemia radiographs are normal. The absence of markedly abnormal haematological values does not exclude the diagnosis. The diagnosis of spontaneous cellulitis of the foot is relatively uncommon in children, it is therefore important to consider immunocompromise in any unexplained infection.

1 Musera G, Carnelli V, Ferruri M, et al. Prognostic significance of radiological bone involvement in childhood
acute lymphoblastic leukaemia. Arch Dis Child acute lympho

2 Simmons CR, Harle TS, Singleton EB. The osseous manifestations of leukaemia in children. Radiol Clin North Am 1968 6:115-30.

3 Clausen N, Gotze H, Pederson A, et al. Skeletal scintigraphy and radiograph at onset of acute lymphocytic leukaemia in childhood. Med Pediatr Oncol 1983;11:291-6.
4 D'Astous J, Corrigan M, Wiley J. The musculoskeletal 'Astous J, Corrigan M, Wiley J. The musculoskeletal manifestations of acute lymphocy
hood. Orthop Trans 1984;8:460.

5 Gunz FW. Epidemiology. In: Gunz FW, Henderson ES, eds. Leukaemia. 4th ed. New York: Grune and Stratton, 1983:17-42

6 Schaller J. Arthritis as a presenting manifestation of malignancy in children. F Pediatr 1972;81:793.

7 Simone J. Blood and blood forming tissues. In: Rudolph AM, Barnett HL, Einhorn AH, eds. Paediatrics. 16th ed. New York: Appleton-Century-Crofts, 1977:1183-91.

8 Heinrich SD, Gallagher D, Warrior R, et al. The prognastic significance of the skeletal manifestations of acute lymphoblastic leukaemia of childhood. F Pediatr Orthop 1994;14: 105-11.

9 Thomas LB, Forkner CE Jr, Frei ER, et al. The skeletal lesions of acute leukaemia. Cancer 1961;14:608.

10 Spilberg I, Meyer GJ. The arthritis of leukaemia. Arthritis Rheum 1972;15:630-5.

11 Calabro JJ. Cancer and arthritis. Arthritis Rheum 1967;10: 553-67.

12 Inman RD, Day WK. Immunological and clinical aspects of immune complex disease. Am f Med 1981;70:1097-106.

13 Saulsbury FT, Sabio H. Acute leukaemia presenting as arthritis in children. Clin Pediatr 1985;24:625-8.

14 Saulsbury FT, Sabio H, Conrad D, et al. Acute leukaemia with features of systemic lupus erythematosus. $\mathcal{F}$ Pediatr with features of

15 Jonsson OG, Sartain P, Ducore JM, et al. Bone pain as an initial symptom of childhood acute lymphoblastic leukaemia: association with nearly normal hematologic indexes. F Pediatr 1990;117:233-7.

16 Wallendal M, Stephen L, Hollister JR. The discriminating value of serum lactate dehydrogenose levels in children with malignant neoplasms presenting as joint pain. Arch Pediatr Adolesc Med 1996;150:70-3. 